DOI 10.37882/2500-3682.2021.11.17

\title{
КОПИНГ-СТРАТЕГИИ ПОВЕДЕНИЯ И СТРЕССОУСТОЙЧИВОСТЬ СТУДЕНТОВ И МОЛОДЫХ СПЕЦИАЛИСТОВ ПРОТИВОПОЖАРНОЙ СЛУЖБЫ
}

\section{COPING BEHAVIOR STRATEGIES AND STRESS RESISTANCE OF STUDENTS AND YOUNG SPECIALISTS OF THE FIRE SERVICE}

\section{E. Tuzhikova}

Summary: The article is devoted to the study of stress resistance and the use of coping strategies of behavior among cadets and young specialists of the fire service, which is relevant and practically significant for professional activity. Cadets and young employees of the Ministry of Emergency Situations took part in the study. It was revealed that cadets in a stressful situation rationally assess the possibilities of effective resolution of a problematic situation. In situations involving increased loads, cadets will resort to the use of intellectual rationalization techniques, switching attention to reduce the subjective significance of intractable situations, which reflects a constructive approach to solving difficulties. For young professionals with work experience, they resort to trying to solve the problem by implementing specific actions aimed at changing the situation.

Keywords: coping behavior, stress, stress tolerance, fire service employees.

\author{
Тужикова Елена Сергеевна \\ К.nсх.н., дочент, Российский государственный \\ педагогический университет им. А.И. Герцена
}

tuzhikova@live.ru

Аннотация: Статья посвящена изучению стрессоустойчивости и использования копинг-стратегий поведения у курсантов и молодых специалистов противопожарной службы, что является актуальным и практически значимым для профессиональной деятельности. В исследовании принимали участие курсанты и молодые сотрудники ГПС МЧС. Было выявлено, что курсанты В стрессовой ситуации рационально оценивают оптимальные возможности решения сложных ситуаций. В ситуациях, связанных с повышенными нагрузками, курсанты будут прибегать к рациональному типу реагирования для снижения трудных и стрессогенных ситуаций и преобразованию их в конструктивный способ, что отражает более адаптивный и менее затратный подход к разрешению трудностей. Для молодых специалистов, имеющих практический опыт работы выработан способ реагирования на стрессогенные ситуации через изменение отношения к ним.

Ключевые слова: копинг-стратегии поведения, совладающее поведение, стресс, стрессоустойчивость, сотрудники противопожарной службы (ГПС $\mathrm{MYC)}$.

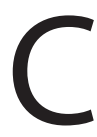

лужебная и боевая деятельность сотрудников ГПС МЧС является одной из самых специфических и опасных сфер профессиональной деятельности. Характерная особенность профессиональной деятельности пожарного проявляется в очевидности социальной ценности и экологической значимости работы. [2]. Сотрудники государственной противопожарной службы часто сталкиваются со стрессогенными ситуациями. Здесь эффективность и безопасность работы спасателей во многом зависит от правильно организованной психологической подготовки: она так же необходима для профилактики угроз психологических и физических травм. [4]

Исследование психологических особенностей профессиональной деятельности пожарных привлекало и привлекает множество психологов [5]. Актуальность проведения данных исследований обуславливается ростом числа техногенных чрезвычайных ситуаций повсеместно. На сегодняшний день они составляют 75-80\% от общего количества чрезвычайных ситуаций. [5]

На сегодняшний день прослеживается тенденция к противоречиям между растущими предъявляемыми к профессионализму требованиями к специалистам государственной пожарной службы МЧС и недостаточностью уровня их психологической готовности к профессиональной деятельности. Психические свойства личности, необходимые для эффективной организации боевых действий в экстремальных условиях, формируются в процессе её учебно-профессиональной и профессиональной деятельности или же заменяются другими качествами. Важно отметить, что некоторые психологические свойства личности пожарного напрямую зависят от профессиональной мотивации, формирование которых происходит в процессе их профессиональной и психологической подготовки. [7]

В современных условиях профессиональная деятельность сотрудников ГПС МЧС стала более интенсивной и трудной. Это связано с внедрением и широким применением новых технических средств, специальной техники. В этих условиях труда пожарные непрерывно подвергаются нагрузкам на физическое и психическое здоровье. Они несут ответственность за здоровье своих коллег и окружающих. Им приходится сталкиваться с массовыми 
человеческими жертвами и значительными материальных потерями. [3]

Профессиональная деятельность сотрудников ГПС МЧС часто сопряжена с воздействием множества неблагоприятных факторов как физических, психологических, так и других патогенных раздражителей, которые способствуют развитию выраженного психоэмоционального и физиологического стресса. Одним из распространённых стрессогенных факторов выступает «режим тревожного ожидания» во время суточного дежурства. Реакция, связанная с беспокойством об ожидании вызова, зачастую больше реакции, которая возникает во время действий в кризисных условиях. [1]

Анализ исследований позволяет раскрыть значимость роли психологической подготовки сотрудников ГПС МЧС к боевой деятельности во время обучения и в первый период адаптации вхождения в профессиональную деятельность. Психологическая готовность не может возникнуть сама - она развивается и сохраняется на протяжении всей служебной деятельности, обучения, тренировок, занятий. Правильно организованная система мероприятий по обеспечению психологической готовности и активизации навыков в сочетании с профессиональными навыками позволяет специалисту быстро и качественно справиться с поставленными задачами. [6]

Таким образом, в процессе становления профессионализма необходимо учитывать психологические особенности личности и степень адаптированности в служебной деятельности не только во время обучения курсантов, но и молодых специалистов. Психологический контроль и объективный анализ факторов психического напряжения позволяет повысить уровень профессиональной подготовки специалистов. Способы реагирования на стресс и стратегии поведения в экстремальных ситуациях требуют внимательного изучения и являются актуальными в современных условиях.

Нами было проведено исследование целью, которого было в определении стрессоустойчивости и способов совладающего поведения. В исследовании приняли две группы испытуемых: первая группа курсантов 5 курса ГПС МЧС в количестве 59 человек (средний возраст 21 год); вторая группа сотрудников ГПС МЧС России в количестве 58 человек Средний возраст 27 лет и стаж работы по специальности не более 5 лет).

В качестве психодиагностического инструментария были использованы следующие методики - методика диагностики состояния стресса А.О. Прохорова, опросник «Утомление - Монотония - Пресыщение - Стресс», адаптированный А.Б. Леоновой и опросник «Способы совладающего поведения» Р. Лазаруса.
В таблице 1 представлены результаты сравнительного анализа среднегрупповых значений по методике совладающего поведения в группах курсантов и сотрудников МЧС.

Как оказалось, способы совладающего поведения конфронтация, дистанцирование, поиск социальной поддержки, принятие ответственности, бегство-избегание достоверно выше в группе курсантов, чем у сотрудников.

Стратегия конфронтации относится к неконструктивному способу реагирования на трудные ситуации, данный способ отражает больше эмоциональный отклик и чаще сопровождается негативными поведенческими реакциями иногда немотивированной агрессивностью и излишней конфликтностью если выражено очень сильно. В умеренном проявлении этот способ является откликом обозначения трудной ситуации и возможностью поразмышлять как наиболее рационально среагировать на трудную ситуацию, что может является побудительным для преобразования или отражения своих интересов, что в свою очередь позволяет снижать повышенную тревожность. Эта стратегия является активным способом борьбы со стрессовыми воздействиями. Средний результат по шкале «Конфронтация» у группы курсантов составляет 55,9, у группы сотрудников 45,9. Эти показатели попадают в зону умеренного использования стратегии.

Средние результаты по шкале «Дистанцирование» у курсантов составляют 56,6, у опрошенных сотрудников 47. Эти показатели попадают в зону умеренного использования стратегии. Это свидетельствует о том что, сотрудники и курсанты предпочитают снизить значимость происходящего. Дистанцирование проявляется в снижении эмоционального реагирования, где может происходить обесценивание своих переживаний и определенное снижение значимости и оптимальных способах реагирования на трудные ситуации.

Средние результаты по шкале «Самоконтроль» у курсантов составляют 41,4, у опрошенных сотрудников 41,55 . Эти показатели попадают в зону умеренного использования стратегии. По данному копингу наблюдается наиболее низкий результат, находящейся на границе с редким использованием стратегии. Суть данного механизма заключается в целенаправленном подавлении чувств и эмоций с целью сохранения оптимального для работы состояния.

Способом совладающего поведения у курсантов и у сотрудников «Поиск социальной поддержки» имеют средние значения, что свидетельствует о необходимости взаимодействия и принятия во внешних контактах, для восстановления внутренних ресурсов и принятия 
Таблица 1.

Сравнительный анализ по способам совладающего поведения в группах курсантов и сотрудников МЧС

\begin{tabular}{|c|c|c|c|c|c|}
\hline \multirow{2}{*}{$\begin{array}{c}\text { Способ совладающего } \\
\text { поведения }\end{array}$} & \multicolumn{2}{|c|}{ Курсанты МЧС } & \multicolumn{2}{|c|}{ Сотрудники МЧС } & \multirow{2}{*}{$\begin{array}{l}\text { Т-критерий } \\
\text { Стьюдента }\end{array}$} \\
\hline & Ср. зн. & Станд. отклонение & Ср. зн. & Станд. отклонение & \\
\hline Конфронтация & 55,9 & 12 & 45,9 & 6,61 & 4,03 \\
\hline Дистанцирование & 56,6 & 11,43 & 47 & 9,48 & 3,49 \\
\hline Самоконтроль & 41,4 & 12 & 41,5 & 9,02 & $-0,02$ \\
\hline $\begin{array}{l}\text { Поиск социальной } \\
\text { поддержки }\end{array}$ & 48 & 13,8 & 40,8 & 10 & 2,22 \\
\hline $\begin{array}{l}\text { Принятие ответствен- } \\
\text { ности }\end{array}$ & 48,5 & 7,19 & 43,3 & 8,65 & 2,49 \\
\hline Бегство-избегание & 54,8 & 10,47 & 48,4 & 9,26 & 2,44 \\
\hline $\begin{array}{l}\text { Планирование реше- } \\
\text { ния проблемы }\end{array}$ & 50,2 & 9,24 & 50,1 & 10,53 & 0,02 \\
\hline $\begin{array}{l}\text { Положительная пере- } \\
\text { оценка }\end{array}$ & 48,8 & 9,01 & 48,2 & 12,10 & 00,2 \\
\hline
\end{tabular}

помощи.

По показателю «Принятие ответственности» у группы курсантов и у группы сотрудников умеренно выражены, но в группе курсантов статистически более выражены. Этот факт говорит о том, что у курсантов еще не сформировался навык к анализу своего поведения и способности принятия излишней ответственности за случившиеся. Здесь возникает риск развития излишней самокритики, чувства вины и неудовлетворенностью. Тогда как сотрудники имеют меньшее значение по этому показателю.

Среднее значение по шкале «Бегство-избегание» у группы курсантов составляет 54,8 балла. У группы сотрудников среднее значение составляет 48,4. Эти показатели попадают в зону умеренного использования стратегии. Как и дистанцирование, данный вид копингстратегии помогает быстро снизить эмоциональное напряжение, сохраняя самообладание, это может помочь при стрессовых воздействиях.

Конструктивный способ совладающего поведения «Планирование решения проблемы» у курсантов и сотрудников имеют практически идентичные результаты и свидетельствуют о сформированности стратегического планирования и равномерного разрешения сложных и стрессогенных ситуаций.

Также конструктивный способ совладающего поведения «Положительная переоценка» у курсантов и у сотрудников имеют практически идентичные результаты и не выявил значимых различий в этих группах. Данная стратегия отчасти схожа с дистанцированием, однако в данном контексте, сотрудники и курсанты, предпочитающие этот способ будут стремиться предавать своим действиям и поступкам больший смысл. Стрессовую ситуацию они также будут рассматривать как что-то, что может дать им необходимый жизненный опыт.

Таким образом, на основании методики «Способы совладающего поведения», предложенной Лазарусом, копинг-стратегии используются примерно в равной степени сотрудниками и курсантами МЧС. Стратегия «Самоконтроль» предпочитается сотрудниками и курсантами нашей выборки меньше, чем остальные стратегии.

Далее были выявлены корреляционные связи и их различия в группах курсантов и сотрудников ГПС МЧС по показателям методики «Диагностика состояния стресса» (А.О. Прохоров), опросник «Утомление - Монотония Пресыщение - Стресс» (А.Б. Леонова) и опросника «Способы совладающего поведения».

В группе курсантов была получена обратная взаимосвязь показателей «Уровень регуляции в стрессовых условиях» со стратегиями «Конфронтация» $(-0,531$; уровень значимости $\mathrm{p}<0,05)$ и «Положительная переоценка» $(-0,557 ;$ уровень значимости $\mathrm{p}<0,05)$. Чем выше показатель уровня регуляции в стрессовых условиях, тем ниже показатели использования копинг-стратегий. Таким образом, курсанты в стрессовой ситуации предпочитают избегать элементов враждебности и конфликтности. Исключение импульсивных реакций в сторону сдержанного поведения, они не испытывают трудностей в планировании действий. Рационально оценивают оптимальные возможности решения сложных ситуаций.

Кроме того, была выявлена прямая взаимосвязь показателей актуального функционального состояния стресса с копинг-стратегиями «Дистанцирование» $(0,649$; уровень значимости р <0,05), «Самоконтроль» $(0,638$; 
уровень значимости $\mathrm{p}<0,05)$ и «Планирование решения проблемы» $(0,485 ;$ уровень значимости $\mathrm{p}<0,05)$. Чем сильнее степень выраженности актуального функционального состояния стресса у курсантов, тем более выражено предпочтение копинг-стратегий «Дистанцирование», «Самоконтроль» и «Планирование решения проблемы». Соответственно, в ситуациях, связанных с повышенными нагрузками, курсанты будут прибегать к снижению эмоционального реагирования, где может происходить обесценивание своих переживаний, определенное снижение значимости и оптимальных способов реагирования на трудные ситуации. Курсанты справляются с проблемой при помощи анализа ситуации и отражают конструктивный подход к разрешению трудностей.

Аналогичным способом был проведен корреляционный анализ в группе сотрудников и была получена прямая взаимосвязь показателей «Уровень регуляции в стрессовых условиях» со стратегией «Планирование решения проблемы» $(0,82 ;$ уровень значимости $p<0,05)$. Чем выше показатель уровня регуляции в стрессовых условиях у сотрудников, тем более выражено предпочтение копинг-стратегии «Планирование решения проблемы». Можно сделать вывод, что сотрудники в стрессовой ситуации чаще прибегают к планированию собственных действий с учетом своего прошлого опыта и имеющихся ресурсов, что отражает конструктивный способ реагирование на трудные ситуации. Кроме того, была выявлена прямая взаимосвязь показателей актуального функционального состояния стресса с копингстратегией «Конфронтация» (0,65; уровень значимости $\mathrm{p}$ $<0,05)$. Чем сильнее степень выраженности актуального функционального состояния стресса, тем более выражено предпочтение копинг-стратегии «Конфронтация». В ситуациях, связанных с повышенными нагрузками, сотрудники МЧС прибегают к изменению ситуации за счет активных действий, что позволяет справляться со стрессогенными ситуациями.

Таким образом, полученные результаты работы выявили, что курсанты в стрессовой ситуации рационально оценивают оптимальные возможности решения сложных ситуаций. В ситуациях, связанных с повышенными нагрузками, курсанты будут прибегать к рациональному типу реагирования для снижения трудных и стрессогенных ситуаций и преобразованию их в конструктивный способ, что отражает более адаптивный и менее затратный подход к разрешению трудностей. Для молодых специалистов, имеющих практический опыт работы выработан способ реагирования на стрессогенные ситуации через изменение отношения к ним.

\section{ЛИТЕРАТУРА}

1. Василюк, Ф.Ё. Психология переживания: анализ преодоления критических ситуаций / Ф.Ё. Василюк. - М.: Изд-во Моск. ун-та, 2011. - 200 с.

2. Дежкина, Ю.А. Развитие профессионально важных качеств сотрудников государственной противопожарной службы МЧС России в процессе профессионализации: автореф. дис. ... канд. псих. наук: 19.00.03 / Ю.А. Дежкина; Рос. гос. пед. ун-т. - СПб., 2008. - 23 с.8

3. Дружилов, С.А. Психология профессионализма человека: интегративный подход / С.А. Дружилов // Журнал прикладной психологии. - 2003. - № 4-5. C. $35-42$

4. Ильинский, С.В. Особенности стрессоустойчивости сотрудников противопожарной службы / С.В. Ильинский, Гладышева Е.В. // Вестник Самарской гуманитарной академии. Серия: Психология. - 2013. - №2. - С. 34-45.

5. Осипов, А.В. Профессионально важные качества сотрудников пожарно-спасательных формирований на разных этапах профессионального становления: автореф. ди. ... канд. псих. наук: 19.00.13 / А.В. Осипов. - Ростов-на-Дону, 2009. - 32 с.

6. Пашов, С.С. Основные задачи психологической подготовки сотрудников ГПС МЧС / С.С. Пашов, И.Д. Черноусова // Проблемы обеспечения безопасности при ликвидации последствий чрезвычайных ситуаций. - 2016. - №1-2. - С. 312-314.

7. Протасов, А.В. Профессионально-важные качества пожарных / А.В. Протасов, И.Д. Черноусова // Современные технологии обеспечения гражданской обороны и ликвидации последствий чрезвычайных ситуаций. - 2014. - №1. - С. 3-6.

(c) Тужикова Елена Сергеевна (tuzhikova@live.ru). 